\section{Disease of Potatoes}

THE Sclerotia referred to by Mr. Worthington G. Smith (in NATURE, vol. xxviii. p. 299) as having destroyed the potatoes in Norway have been sent to me from two different places on our western coast. As I usually travel every summer, I had no opportunity of cultivating them myself; so I sent them to Prof. De Bary of Strasburg, who kindly informs me that he has cultivated them with success. They belong to Peziza sclerotionum (Lib.). The spores of our Norwegian Peziza will produce Sclerotia, as he has proved by experiment, also in Daucus carota, and very likely in Phaseolus and some other plants.

Christiania, August 6

A. BlytT

\section{Determination of " $H$ "}

SINCE the publication of a method for the determination of the value of the horizontal component of the earth's magnetism by Mr. A. Gray in NATURF, vol. xxvii. p. 32, I have worked out the value of " $H$ " for my laboratory here, and from six sets of experiments carried ont during the month of March in a small building constructed free from iron near the laboratory, I find " $H$ " to equal $0 \cdot 18365$. The method proposed by Gray was closely adhered to throughout the experiments.

Taunton, August 8 FREDERIC JOHN SMITH

\section{Fireball}

ABOUT 8.25 p.m. on the IIth inst. my attention was suddenly attracted in the direction of the window of my dining-room, which looks south, by a brilliant ball of fire of a deep amethyst colour. It was travelling across the clear blue sky at the rate of about twenty miles an hour in an easterly direction and at an angle of $45^{\circ}$. Before disappearing behiıd a cloud it seemed to throw a few particles of itself forwards at a greater speed than that at which it was travelling. I trust others saw it under more favourable circumstances, and that they will communicate thei experience of its course to you.

The Lawns, Highgate, August I4

\section{Palæolithic Implements at Stratford}

ALLow me to say that a few weeks ago I found an abraded ochreous oval Palæolithic implement at Stratford (in situ two feet from : urface). I have shown it to Mr. W. G. Smith, who says it is very interesting, as implements are rare in that locality, and especially oval ones, and he thought it as well for me to communicate with you, as it may interest some of your readers.

49, Beech Street, E. C.

G. F. LAWRENCE

\section{EARTH PULSATIONS}

$\mathrm{E}$

$\mathrm{R}$ many years philosophers have speculated as to whether the surface of the earth is really so stable as it usually appears. With the sudden and violent motions of our soil which we call earthquakes man has been familiar since the earliest times, and the origin of these disturbances has always formed a fruitful source of speculation. With the help of properly constructed instruments, our knowledge of the nature of these movements has during the last few years been greatly extended, and we are brought to the conclusion that these natural vibrations are propagated through the surface of our earth in a manner very different to that which we should have anticipated from our knowledge of elastic solids. Another order of earth movements which, in the hands of Timoteo Bertelli of Florence, M. S. di Rossi of Rome, and other Italian investigators, have recently received considerable attention, are Earth Tremors. From observations carried on during the past ten years it would appear that the soil of Italy is practically in a perpetual state of vibration, even in districts far removed from volcanic centres. On account of the smallness in the amplitude of these motions they are only to be observed with the aid of specially constructed instruments. Messrs. George and Horace Darwin, in connection with their experiments on the disturbance of gravity caused by lunar attraction, have shown that these movements are common to the soil of Britain. Like observa- tions have been made in Japan, and it does not seem improbable that after further experiments have been carried out we shall be brought to the conclusion that the surface of the whole globe is affected with similar microseismical disturbances.

In addition to these minute movements, which escape the attention of the ordinary observer on account of the smallness of their amplitude, theoretical investigation has shown that there may be existing in the soil on which we live movements which have escaped our attention on account of the slowness of their period. These motions for want of a better term I call Earth Pulsations. Mr. George Darwin in his last report to the British Association has shown that movements of that nature may be produced by barometrical variation. A rise of the barometer over an area is equivalent to loading that area with a weight, in consequence of which it is depressed. When the barometer falls, the load is removed from the area, which in virtue of its elasticity rises to its original position. This fall and rise of the ground completes a single pulsation.

On the assumption that the earth is extremely rigid, Mr. Darwin calculates that if the barometer rises an inch over an area like Australia, the load is sufficient to sink that continent two or three inches.

The tides which twice a day load our shores cause the land to rise and fall in a similar manner. On the shores of the Atlantic, Mr. Darwir has calculated that this rise and fall of the land may be as much as five inches. By these risings and fallings of the land the inclination of the surface is so altered that the stile of a plummet suspended from a rigid support ought not always to hang over the same spot. There would be a deflection of the vertical

In short, calculation respecting the effects of loads of various descriptions which we know are by natural operations continually being placed upon and removed from the surface of various areas of the earth's surface, indicate that slow pulsatory movements of the earth's surface must be taking place, causing variations in inclination of one portion of the earth's crust relatively to another. That pulsatory motions of this description have repeatedly been observed it may be shown that there is but little doubt. The magnitude of these disturbances however is so great that we can hardly attribute their origin solely to the causes which have just been indicated. Rather than seeking an explanation from agencies exogenous to our earth we might perhaps with advantage appeal to the endogenous phenomena of our planet. When the barometer falls, which we have shown corresponds to an upward motion of the earth's crust, we know from the results of experiment that microseismic motions are particularly noticeable.

As a pictorial illustration of what this really means, ne may imagine ourselves to be residing on the loosely fitting lid of a large cauldron, the relief of the external pressure over which increases the activity of its internal ebullition; the jars attendant on this ebullition are gradually propagated from their endogenous source to the exterior of our planet. This travelling outwards would take place much in the same way that the vibrations consequent to the rattle and jar of a large factory slowly spread themselves farther and farther from the point where they were produced.

Admitting an action of this description to take place, it would then follow that this extra liberation of gaseous material beneath the earth's crust would result in an increased upward pressure from within, and a tendency on the part of the earth's crust to elevation. If we accept this as an explanation of the increased activity of a tremor indicator, then such an instrument may be regarded as a barometer, measuring by its motions the variations in the internal pressure of our planet.

The relief of external pressure and the increase of the 
internal pressure it will be observed both tend in the same direction, namely, to an elevation of the earth's crust.

This explanation of the increased activity of earth tremors which is I believe due to M. di Rossi, is here only advanced as a speculation-more probable perhaps than many others. We know how a mass of sulphur which has been fused in the presence of water, in a closed boiler, gives up in the form of steam the occluded moisture upon the relief of pressure. In a similar manner we see steam escaping from volcanic vents and cooling streams of lava. We also know how gas escapes from the pores and cavities in a seam of coal on the fall of the baroinetrical column. We also know that certain wells increase the height of their column under like conditions. The latter of these phenomena may be added to that which we have already mentioned, as a result consequent on diminution of atmospheric pressure, which, by its tendency to render an area of less weight, facilitates its rise.

The next question is as to whether we have any cirect evidence of such heavings and sinkin ss in our earth's crust.

Although some of the proofs which are brought forward to show that slow pulsations like these are phenomena which have been repeatedly observed are unsatisfactory, taking them one with another they indicate that these pulsatory phenomena have a real existence.

Pendulums for instance which have been suspended for the purposes of seismometrical observations, have, both by observers in Italy and Japan, been seen to have moved a short distance out from and then back to their normal position.

This motion has simply taken place on one side of their central position, and is not due to a swing. The character of these records is such that we might imagine the so:l on which the support of the pendulum had re,ted to have been slowly tilted and slowly lowered. They are the most marked on those pendulums provided with an index writing a record of its motions on a smok d glass plate, which index is so arranged that it gives a multiplied representation of the relative motion between it and the earth. As motions of this sort might be possibly due to the action of moisture in the soil tilting the support of the pendulum, and to a variety of other accidental causes, we cannot insist on them as being certain indications that there are slow tips in the soil, but for the present allow them to remain as possible proofs of such phenomena.

Evidences of displacements of the vertical which are more definite than the above are tho e made by Bertelli, Rossi, Count Malvasi, and other Italian observers, who, whilst recording earth tremors, have spent so much time in watching the vibrations of stiles of delicate pendulums by means of microscopes. As a result of these observations we are told that the point about which the stile of a pendulum oscillates is variable. These displacements take place in various azimuths, and they appear to be connected with changes of the barometer.

From this and from the fact that it is found that a number of different pendulums differently situated on the same area give similar evidence of these movements, it would hardly seem that this phenomena could be attributed to changes in temperature, moisture, and the like. M. S. di Rossi lays stress on this point, especially in connection with his microseismograph, where there are a number of pendulums of unequal length which give indications of a like character. The directions in which these tips of the soil take place, which phenomena are noticeable in seismic as well as microseismic motions, Rossi states are related to the direction of certain lines of faulting.

Bubbles of delicate levels when examined by a microscope change their position with meteorological variations, but Rossi also tells us that they change their position, sometimes not to return for a long time during a microseismic storm. Here again we have another phenomena pointing to the fact that microseismic disturbances are the companions of slow alterations in level. ${ }^{1}$

The more definite kinds of information which we have to bring forward, tending to prove the existence of earth pulsations too slow in period to be felt, are those which appear to be resultant phenomena of great earthquakes.

The phenomena that we are certain of in connection with earth vibrations, whether these vibrations are produced artificially by explosions of dynamite in bore holes, or whether they are produced naturally by earthquakes, are, firstly, that a disturbance as it dies out at a given point often shows in the diagrams obtained by seismographs a decrease in period; and secondly, a similar decrease in the period of the disturbance takes place as the disturbance spreads.

As examples of these actions I will refer to the diagrams which I have given in a paper on the "Systematic Observation of Earthquakes" in vol. iv. of the Transactions of the Seismological Society of Japan.

-In a diagram of the disturbance of March I, I882, it seems that the vibrations at the commencement of the disturbance had a period of about 3 per second, near the middle of the disturbance the period is about $I \cdot r$, whilst near the end the period has decreased to 46 . That is to say, the back and forth motion of the ground at the commencement of the earthquake was six times as great as it was near the end, when to make one complete oscillation it took between two and three seconds. Probably the period became still less, but was not recorded owing to the insensibility of the instruments to such slow motions.

We have not yet the means of comparing together diagrams of two or more earthquakes, one having been taken near to the origin and the other at a distance. The only comparisons which I have been enabled to make have been those of diagrams taken of the same earthquake--one in Tokio and the other in Yokohama. As this base is only sixteen miles, and the earthquake may have originated at a distance of several hundreds of miles, comparisons like these can be of but little value.

The best diagrams to illustrate the point I wish to bring forward are those at the end of the paper just referred to. These are the results obtained at three stations in a straight line, but at different distances from the origin, of a disturbance produced by exploding a charge of dynamite in a bore hole. A simple inspection of the diagrams shows that at the near station the disturbance consisted of back and forth motions which, compared with the same disturbance as recorded at a more distant station, were very rapid. Further, by examining the diagram of the motions, say at the near station, it is clearly evident that the period of the back and forth motion rapidly decreased as the motion died out.

Then illustrations are given, as examples out of a large series of other records, all showing like results.

Although we must draw a distinction between earth waves and water waves, we yet see that in these points they present a striking likeness. Let us take, for example, any of the large earthquake waves which have originated off the coast of South America, and then radiated outwards, until they spread across the Pacific, to be recorded in Japan and other countries perhaps twenty-five hours afterwards, at a distance of nearly 9000 miles from their origin. Near this origin they appeared as walls of water, which were seen rapidly advancing towards the coast. These have been from 20 to 200 feet in height, and they succeeded each other at rapid intervals, until finally they died out as gentle waves. By the time these walls of water traversed the Pacific to, let us say, Japan, they

I Since my return to Japan in January, $188_{3}$, I may mention that I bave commencer series of observations on earth tremors and earth pulsati ns, and on several cccasions have observed very marked coincidences between barometrical d pressions and these movements. $N_{1} t$ only are these atmospheric changes accompanied with microseismic storms, but there are deflections in the stile of a pendulum, and changes in the pcsiti $n$ of the bulbs of delicate levels, which at such times can be seen with the naked eye to SURGE back and forth through a small range. 
broadened out to a swell so flat that it could not be detected on the smoothest water excepting along shore lines, where the water rose and fell like the tide. Instead of a wall of water 60 feet in height we have long flat undulations perhaps 8 feet in height, but with a distance from crest to crest of more than 120 miles.

If we turn to the effects of large earthquakes as exhibited on the land, I think that we shall find records of phenomena which are only to be explained on the assumption of an action having taken place analogous to that which takes place so often in the ocean, or an action similar to that exhibited by small earthquakes and artificially produced disturbances if greatly exaggerated.

As a remarkable instance of such phenomena we may take the great earthquake of Lisbon on November I, I755. In Spain, Northern Italy, the South of France and Germany, Northern Africa, Madeira and other Atlantic Islands, the effects of the disturbance which created so much devastation in Portugal were also more or less severely felt as violent movements of the soil.

In other countries further distant, as, for instance, Great Britain, Holland, Norway and Sweden, and North America, although the records are numerous, the only phenomena which were particularly observed were the slow oscillations of the waters in lakes, ponds, canals, \&c. In some instances the observers especially remarked that there was no motion in the soil.

Pebbly Dam in Derbyshire, which is a large body of water covering some 30 acres, commenced to oscillate as a strong current from the south.

A canal near Godalming flowed 8 feet over the walk on the north side.

Coniston Water in Cumberland, which is about five miles long, oscillated for about five minutes, rising a yard up its shores. Near Durham a pond 40 yards long and ro yards broad rose and fell about I font for six or seven minutes. There were four or five ebbs and flows per minute.

Loch Lomond rose and fell through about $2 \frac{1}{2}$ feet every five minutes, and all other lochs in Scotland seem to have been similarly agitated.

At Shirbrun Castle in Oxfordshire, where the water in some moats and ponds was very carefully observed, it was noticed that the floods began gently, the velocity then increased, till at last with great impetuosity they reached their full height. Here the water remained for a little while, until the ebb commenced, at first gently but finally with great rapidity. At two extremities of a moat about 100 yards long it was found that the sinkings and risings were almost simultaneous. The motions in a pond a short distance from the moat were also observed, and it was found that the risings and sinkings of the two did not agree.

During these motions there were several maxima.

These few examples of the motions of waters without any record of the motions of the ground at the time of the Lisbon earthquake must be taken as examples of a very large number of similar observations of which we have detailed accounts.

Like agitations it must also be remembered were perceived in North America and in Scandinavia, and if the lakes of other distant countries had been provided with sufficiently delicate apparatus, it is not unlikely that like disturbances would have been recorded.

The only explanation for these phenomena appears to be that the short quick vibrations which had ruined so many cities in Portugal had by the time that they had radiated to distant countries gradually become changed into long flat waves having a period of perhaps several minutes, and in countries like England these pulse-like movements were too gentle to be perceived excepting in the effects produced by tipping up the beds of lakes and ponds.

The phenomenon was not unlike that of a swell produced by a distant storm.
At Amsterdam and other towns chandeliers in churches were observed to swing. At Haarlem floods rose over the sides of tubs, and it is expressly mentioned that no motion was perceived in the ground.

At the Hague a tallow chandler was surprised at the clashing noise made by his candles, and this the more so because no motion was felt under foot.

At Toplitz the pulsation of the ground appears to have manifested itself in effects upon the springs. The flow of the principal spring was greatly increased. Before this increase it became turbid, and at one time stor pcd. Subsequently it became clear, and flowed as usual, but the water was hotter and more strongly mineralised.

At one or two places, as, for instance, in Britain, slight earthquakes were experienced. These, however, were local, and in every probability were secondary disturbances produced by the pulsations causing ground in a critical state to give way.

In this earthquake I think, then, that we have a clear case of the production of pulsations in the soil that were too slow to be felt by ordinary observers.

Motions like these might be called slow earthquakes, and it does not seem unlikely that they are the resultants of all large disturbances. When they accompany a large earthquake like that of Lisbon, their cause is evident. But when we see the waters of lakes and ponds oscillating, the bulbs of levels disturbed, and the plummet line of pendulums displaced, the reason of these phenomena are not so apparent. It would seem possible that in some cases pulsations producing these phenomena might have their origin beneath the oceans, or deep down beneath the earth's crust. Perhaps, instead of commencing with the snap and jar of an earthquake, they may commence as a heaving or sinking of a considerable area, which may be regarded as an uncompleted effort in the establishment of an earthquake or a volcano. The very fact that we know that volcanoes rising from deep oceans have in the first instance forced their way against a pressure of at least three or four tons to the square inch, indicates to us the existence of internal pressures tending to raise the crust of the earth, which pressures are infinitely greater than any of the pressures which we have upon the surface of our earth produced by tides and variations in the barometrical column. If we follow the views of Mr. Mallet in considering that the pressures exerted on the crust of our earth may in volcanic regions be roughly estimated by the height of a column of lava in the volcanoes of such districts, we see that in the neighbourhood of a volcano like Cotopaxi the upward pressures must have been many times greater than the pressures already mentioned-sea level being taken as the line of hydrostatic equilibrium. The chief point, however, is that beneath the crust of our earth enormous pressures exi t tending to cause eruption; and farther, that these are variable. Before a volcano bursts forth we should expect that there would be in its vicinity an upward bulging of the crust, and after its formation a fall. Farther, it is not difficult to conjecture other possible means by which such pressures may obtain relief.

Should these pressures then find relief without rupturing the surface, it is not difficult to imagine them as the originators of vast pulsations which may be recorded on the surface of the earth as wave like motions of slow period similar to the motions in the outer area of a tract disturbed by a destructive earthquake.

That slow, undulatory motions or changes in the vertical do occur in the crust of the earth, whatever may be their origin, we have numerous phenomena which certainly admit of explanation on such an assumption.

In Switzerland from time to time we hear of oscillations in the waters of lakes known under the name of Rhussen and Seiches. These, it may be remarked, are common to the lakes and inland seas of many countries.

Other examples of what may have been a slow oscil- 
lating motion of the earth's crust are referred to by Mr. George Darwin in his Report to the British Association in 1882. One of them was made by M. Magnus Nyrén at Pulkova, who, when engaged in levelling the axis of a telescope, observed spontaneous oscillations in the bulb of the level.

This was on May Io (April 28), 1877. The complete period was about twenty seconds, the amplitude being $I^{\prime \prime} 5$ and $2^{\prime \prime}$. One hour and fourteen minutes before this he observes that there had been a severe earthquake at Iquique, the distance to which in a straight line was Io,600 kilometres, and on an arc of a great circle 12,500 kilometres.

On September $20(8)$ in $1867 \mathrm{Mr}$. Wagner had observed at Pulkova oscillations of $3^{\prime \prime}$, seven minutes before which there had been an earthquake at Malta.

On April 4 (March 23), I868, an agitation of the level had been observed by M. Gromadzki, five minutes before which there had been an earthquake in Turkestan.

Similar observations had been made twice before. These, however, had not been connected with any earthquakes, at least--Mr. Darwin remarks-with certainty.

Like phenomena are mentioned by M. S. di Rossi, in his "Meteorologica Endogena."

Thus on March $20,188 \mathrm{r}$, at 9 p.m, a watchmaker in Buenos Ayres observed that all his clocks oscillating north and south suddenly began to increase their amplitude, until some of them became twice as great as before. Similar observations were made in all the other shops. No motion of the errth was detected. Subsequently it was learnt that this corresponded with an earthquake in Santiago and Mendeza.

Another remarkable example illustrating the like phenomena are the observations which were made on December 2I, I860, by means of a barometer in San Francisco, which oscillated, with periods of rest, for half an hour. No shock was felt, nor is it likely that it was a local accident, as it could not be produced artificially. On the following day, however, a violent earthquake was experienced at Santiago.

This brings me to the end of the few important illustrations of the phenomena of earth pulsations which I have at my disposal. With a little trouble I have no doubt that these might be greatly multiplied. As they stand, however, I think that they are quite sufficient to convince us of the existence of phenomena which hitherto have been almost entirely overlooked. That disturbances of the vertical are from time to time produced by long pulse-like waves can, with these examples before us, hardly be doubted. It must, however, be noted that they are of a different order to those phenomena which were so carefully sought for by the Darwins at Cambridge.

Tokio, Japan

\section{ON THE SUPPOSED HUMAN FOOTPRINTS RECENTLY FOUND IN NEVADA 1}

DRING the past summer various accounts have been published of the discovery of human footprints in sandstone rear Carson, Nevada. The locality is in the yard of the State prison, and the tracks were uncovered in quarrying stone for building purposes. Many different kinds of tracks were found, some of which were made by an animal allied to the elephant; some resembled those of the horse and the deer; others were apparently made by a wolf. There were also tracks made by large birds.

The footprints occur in series, and are all nearly in the same horizon. Some of the smaller tracks are sharp and distinct, but most of the impressions are indefinite in outline, owing apparently to the fact that the exact surface on which they were made is not usually exposed.

1 Abstract of a paper read before the National Academy of Sciences, at New York, November 57, r882.
The supposed buman footprints are in six series, each with alternate right and left tracks. The stride is from two and a half to over three feet in extent. The individual footprints are from eighteen to twenty inches in length, and about eight inches wide. The distance between the line of right-hand and left-hand tracks, or the straddle, is eighteen to nineteen inches.

The form and general appearance of the supposed human tracks is shown in Fig. 2, which is a reduced copy of one of the impressions represented by Dr. W. H. Harkness, in his paper before the California Academy of Sciences, August 7, I882. The shaded portion was restored by him from other footprints of the series. A

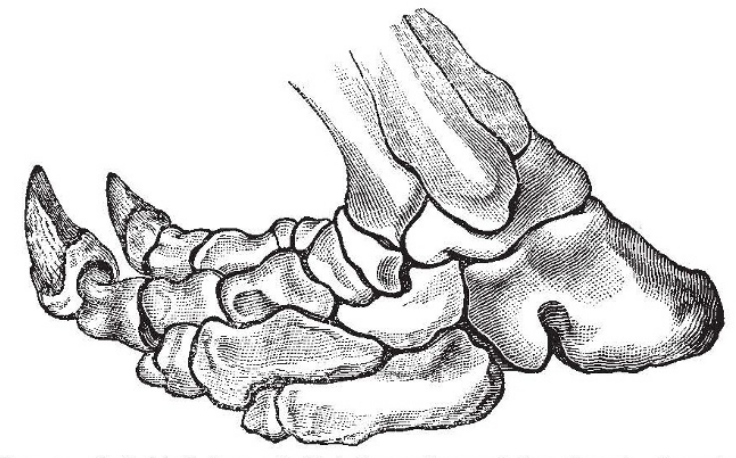

FIG. x.- Left hind foot of Mylodon robustus (after Owen). One-sixth natural size.

copy of this impression was given also by Prof. Joseph Le Conte, in his paper before the same Society, August 27, I882.

The size of these footprints, and especially the width between the right and left series, are strong evidence that they were not made by men, as has been so generally supposed.

A more probable explanation is that the impressions are the tracks of a large sloth, either Mylodon or Morotherium, remains of which have been found in essentially the same horizon. In support of this view it may be said that the footprints are almost exactly what these animals would make if the hind feet covered the impressions of

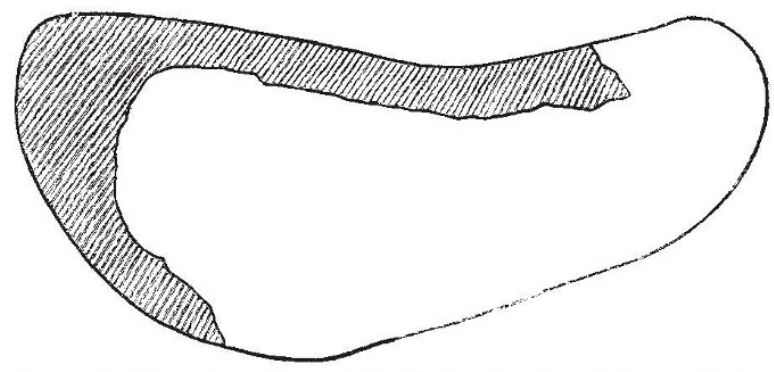

Fig. 2. - Left footprint at Carson (after Harkness). One-sixth natural size.

those in front. In size, in stride, and in width between the right and left series of impressions, the footprints agree closely with what we should expect Mylodon or Morotherium to make. In Fig. I the bones of the left hind foot of a species of Mylodon are represented, the figure being reduced to the same scale as the accompanying cut, Fig. 2, of one of the supposed human footprints.

The geological horizon of these interesting footprints is near the junction of the Pliocene and Quaternary. The evidence, at present, appears to point to the Equus beds of the upper Pliocene as the nearest equivalent.

Since the above communication was read, the writer has had an opportunity of examining photographs and casts of the Carson footprints, and is confirmed in his opinion that the supposed human tracks were made by large 